-------مجلة علوم الرافدين، المجلد 27، العدد 1، ص 10 -16، 2018------

تأثير حامض الستريك على بعض المتغيرات الكيموحيوية في ذكور الأرانب

\author{
انتصار غانم طه \\ قسم العلوم/ كلية التربية الأساسية/ جامعة الموصل
}

(أستلم 2013/9/29 ؛ (2014/3/ 10 (

\title{
الملخص
}

تضمن البحث دراسـة التأثيرات الجانبيـة لحامض الستريك من خـلا إعطاء تراكيز مختلفة وبفترات زمنية على بعض

المتغيرات الكيموحيوية التي لها علاقة بوظائف الكبد في مصل ونسيج الكبد.

استخدمت في هذا البحث ذكور الأرانب المحلية السليمة بعمر 6 أثشهر تراوحت أوزانها ما بين 1- 1.5 كغم حيث تم

توزيعها بصورة عشوائية على مكررات لأربع مجاميع بواقع ستة أرانب لكل مجموعة، شملت المعاملات الآثية:

المجموعة الأولى تم تجريعها ماء مقطر واعتبرت كمجموعة سيطرة، المعاملة الثانية جرعت حامض الستريك بتركيز 250

ملغم حامض الستريك /كغم من وزن الجسم، المعاملة الثالثة جرعت 500 ملغم حامض الستريك /كغم من وزن الجسم والمعاملة الرابعة جرعت 1000 ملغم حامض الستريك /كغم من وزن الجسم، تمت إضافة الحامض منف مع ماء الثرب لكل المجاميع لمدة 30 يوم مع نوفير العلف بصورة حرة أمام الحيوانات طيلة فترة البحث.

ثم سحب الدم وفصل بعد 15 يوم و 30 يوم من المعاملة لأجل الحصول على المصل لإجراء الفحوصات الكيموحيوية ثم قتلت الحيوانات بعد انتهاء المعاملة للحصول على عضو الكبد بعد 30 يوم من المعاملة.

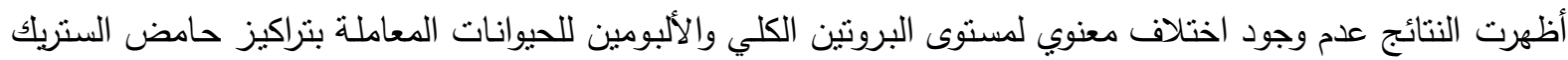

المستخدمة وبفترات مختلفة مقارنة مع مجموعة السيطرة.

كذلك أظهرت النتائج ارتفاعا معنويا لفعالية الانزيمات الناقلة لمجموعة الامين (الالنين ترانس امينز ALT والانئ ترانس امينز AST في مصل الدم)، ومستوى المالونالديهايد MAD في نسيج الكبد بزيادة تراكيز حامض الستريك مع زيادة فئنة فئرة المعاملة (15يوم و 30 يوم) مقارنة مع مجموعة السيطرة. في حين حدث انخفاض معنوي بمستوى الكلوثايثون GSH في في نسيج الكبد بزيادة تراكيز الحامض وزيادة فترة المعاملة مقارنة مع مجموعة السبطرة فيطرة.

الكلمات الدالة: حامض الستريك، البروتين الكلي، الالبومين، الانزيمات الناقلة لمجموعة الامين، المالونالديهايد، الكلوثايثون.

\section{The Effect of Citric Acid on some Biochemical Parameters in Male Rabbit}

\section{Intisar G. Taha}

Department of Science/ College of Basic Education/ University of Mosul

\begin{abstract}
The research includes the study of side effect of citric acid by giving different concentrations at various duration time on some biochemical parameters which has related to the liver function in serum and tissue of liver.

Six month aged healthy male rabbits with weight ranged between 1-1.5 kg were used in this research. They were distributed randomly into four groups; The first group was given distilled water as a control group, the second group was given a dose of $250 \mathrm{mg} / \mathrm{kg}$ of body weight of citric acid,
\end{abstract}




$$
\text { انتصار غانم طه }
$$

the third group was given a dose of $500 \mathrm{mg} / \mathrm{kg}$ of body weight of citric acid and the fourth group was given a dose of $1000 \mathrm{mg} / \mathrm{kg}$ of body weight of citric acid.

Acid was added to drinking water of all groups for 30 days with providing food freely to the animals as long as the experiment lasted. After blood was drawn out and serum was taken male rabbits were killed.

The results showed that no signification in level of total protein and albumin in different concentration and different duration time comparing with the control group. A lso the results showed significant increase of alanine aminotransferase ALT and aspartate aminotransferase AST activity, and malonaldehyed MAD in liver tissue compared with the control group. A significant decrease in the level of glutathione GSH in liver tissue was also seen comparing with the control group with increase concentration of citric acid and increase duration time of treatment.

Keywords: Citric Acid, Total protein, Albumin, ALT, AST, MAD, GSH.

\section{المقدمة}

يتعرض الإنسان يومياً إلى العديد من المركبات والمعقدات الكيميائية في طعامه وشرابه، وقد تكون هذه المواد طبيعية أو يتم

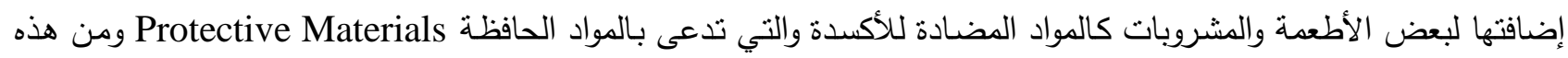

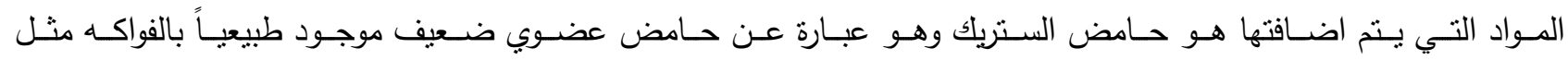
الليمون(Penniston et al., 2008; Lotfy et al., 2007; Garden et al ., 2003). ويعتبر حامض السنريك مادة حافظة طبيعية نستخدم لإضافة المذاق الحامضي للأطعمة والمشروبات ويدخل كذلك في

صناعة مواد التجميل والعطور والمنظفات(Berovic and Legisa, 2007; Frank and Venhoff, 2005).

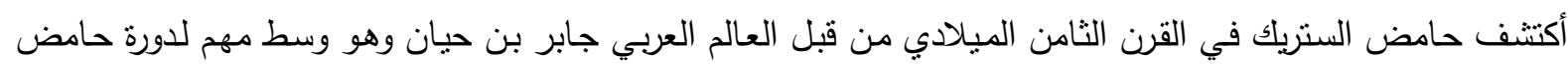
الستريك أو دورة كريبس أو ما تسمى بدورة الحامض الثثلاتي الكاربوكسيل، وتعد هذه الدورة مهمة لأيض المركبات الحياتية مثل فئل

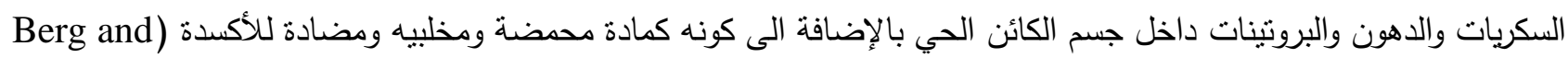

(Thmocykal, 2002

الاسم النظامي للحامض هو 2-Hydroxypropante او 1,2,3 Tricarboxylic Acid<smiles>CC(O)(CC(=O)O)C(=O)O</smiles>

.(Derewenda and Zygmunt, 2007; Hu et al., 2010)

تعد الكميات العالية من حامض الستريك مؤثرة على الثعر والجلد وتآكل مينا الأسنان وكذلك يلعب دوراً مهما في تتظيم ضغط الدم والفشل الكلوي (Frank and Venhoff, 2005) واستتاداً إلى ما تقدم فقد هدف البحث إلى معرفة تأثنير التراكيز المختلفة من حامض الستريك وبفترات مختلفة على بعض المتغيرات الكيموحيوية التي لها علاقة بوظائف الكبد في دم ونسج ذكور 


\section{المواد وطرائق العمل}

استخدم في هذه الدراسـة 24 حيوانـا من ذكور الأرانب المحلية بعمر 6 أنثهر وتراوحت أوزانها مـا بين 1- 1.5 كغم ووضعت في اقفاص بلاستيكية خاصـة وتحت ظروف مختبريه جيدة من التهوية والحرارة والضوء وغذيت الحيوانات طوال فترة الدراسة على العليقة التجارية، وبعدها قسمت الحيوانات إلى أربع مجاميع وبواقع 6 حيوان لكل مجموعة. المجموعة الأولى: جرعت ماء مقطر واعتبرت كمجموعة سبطرة. المجموعة الثانية: جرعت حامض الستريك بتركيز 250 ملغم/كغم من وزن الجسم. المجموعة الثالثة: أعطيت حامض الستريك بتركيز 500 ملغم/كغم من وزن الجسم. المجموعة الرابعة: أعطيت حامض الستريك بتركيز 1000 ملغم/كغم من وزن الجسم. تمت إضافة الحامض مع ماء الثرب لكل المجاميع لمدة 30 يوم.

\section{جمع النماذج وحفظ العينات}

بعد معاملة الأرانب وانتهاء مدة المعاملة، نم الحصول على عينات الدم من قلب الأرانب باستخدام محقنة طبية سعة 5 مل جمعت عينات الدم بعد مرور 15، 30 يوم لغرض الحصول على مصل الدم لإجراء الفحوصات الكيموحيوية المختلفة، وفي نهاية فترة المعاملة ذبحت الحيوانات عن طريق الخلع العنقي واستخراج الكبد لغرض تقدير مسنوى الكلوتايثون والمالونالديهايد. الفحوصات الكيموحيوية

1 - تقدير البروتين في مصل الدم كمبر

قدرت كمية البروتين في مصل الدم بالاعتماد على طريقة بايوريت باستخدام عدة التحليل الجاهزة من شركة BioMerieux الفرنسية) (Kingsley, 1949) 2- تقدير الألبومين في مصل الدم

قدرت كمية الالبومين في مصل الدم وباستخدام بروموكريسول الاخضر بالاعتماد على عدة التحليل جاهزة من شركة

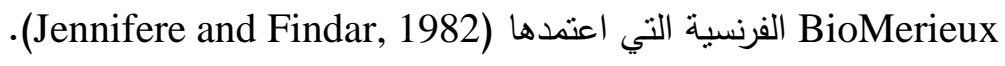
3- تقدير فعالية انزيم الانين ترانس امينز (ALT) قدرت فعالية الانزيم باستخدام طريقة اللونية وبالاعتماد على عدة التحليل الجاهزة من شركة Reitman and ) BioMerieux .(Frankel, 1957 4- تقدير فعالية انزيم الاسبارتيز ترانس امينيز (AST)

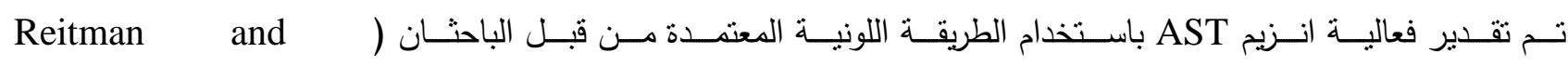

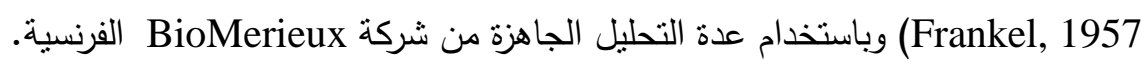
5- مستوى الكلوتايثون في نسيج الكبد تم تقدير مستوى الكلوتايثون في نسيج الكبد باستخدام طريقة المان المحورة (Moron et al., 1979).

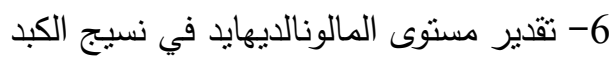
تم تقدير مستوى المالونالديهايد في نسيج الكبد باستخدام طريقة حامض الثايوباربيتورك بالاعتماد على طريقة الباحث

.(Gilbert et al., 1984) 
حلت النتائج إحصائيا بمقارنة مجاميع حامض الستريك مع مجموعة السيطرة: unpaired t-Test

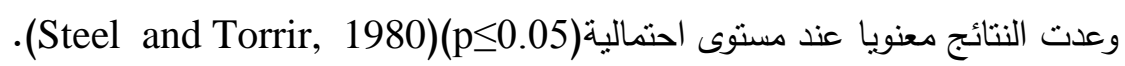

\section{النتائج والمناقشة}

يبين الجدول (1) ان معاملة الأرانب بتراكيز مختلفة من حامض الستريك 250-1000 ملغم/كغم من وزن الجسم يؤدي

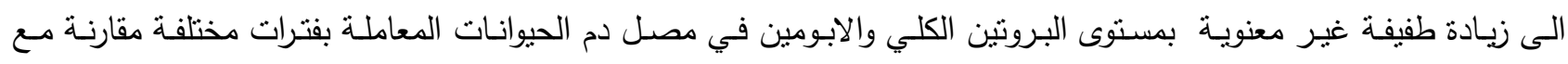
مجموعة السيطرة، وقد يعود هذا الى ان حامض الستريك يعمل على تحليل البروتينات في الكبد وهذه النتائج تتفق مع النتائج التي

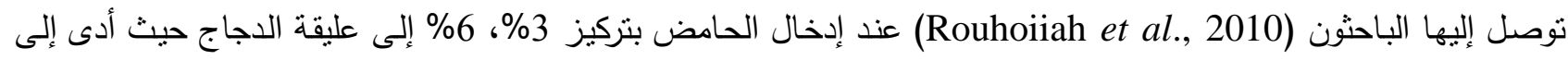
زيادة تركيز البروتين في دم الحيوانات.

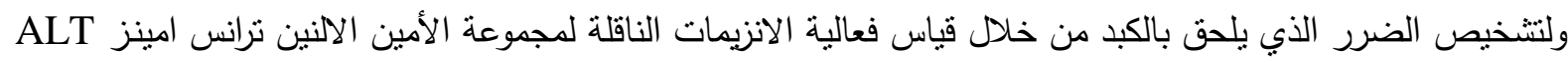

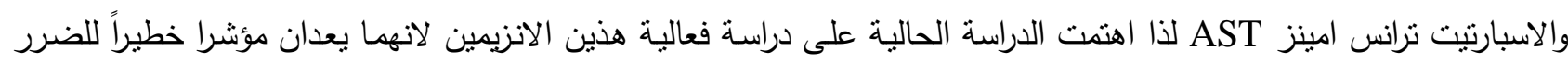

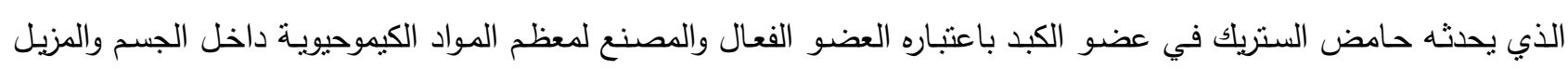
للعديد من المواد السمية من خلال العمليات الايضية التي يقوم بها.

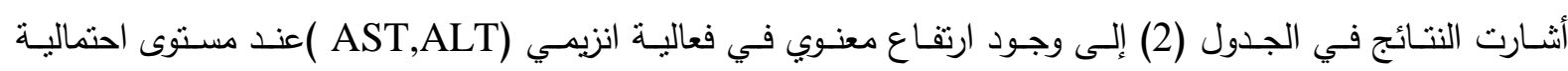

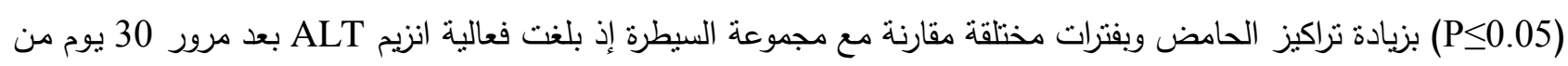

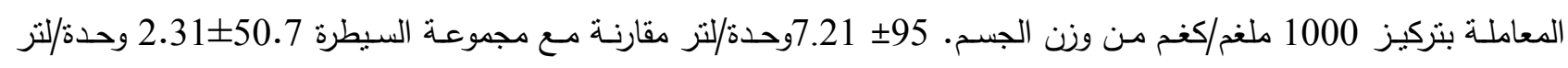
وبلغت فعالية انزيم 8.137 AST وحدة/لتز بعد مرور 30 يوم من المعاملة بتركيز 1000ملغم/كغم من وزن الجسم مقارنة مـع

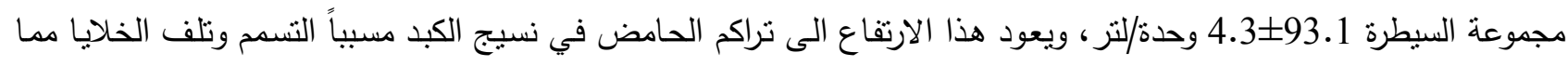

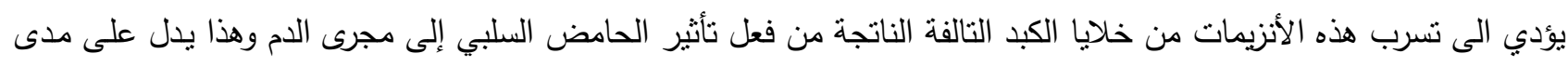

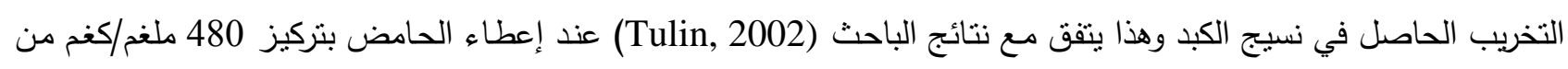
وزن الجسم للفئران المختبرية لمدة 10 أيام وكذلك حدث انخفاض بوزن عضو الكبد للحيوانات المعاملة مقارنة مع مجموعة السيطرة

.(Aktac et al., 2003; Aktac et al., 2002)

كما أدت معاملة الأرانب بحامض الستريك بتراكيز مختلفة وبفترات مختلفة ارتفاعاً معنوياً بمستوى المالونالديهايد

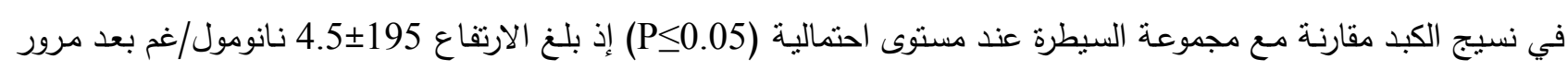

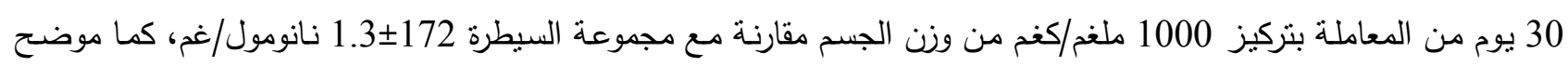

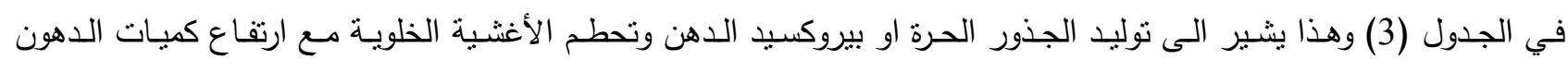

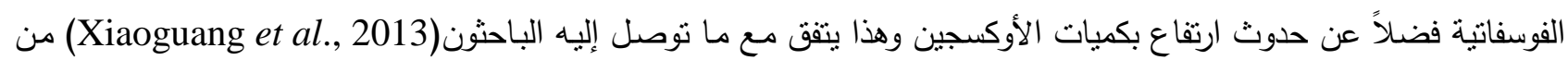
ان إضافة حامض الستريك بتراكيز مختلفة أدى إلى ارتفاع مستوى المالونالديهايد في نسيج الكبد الرطب وارتقاع مستوى تركيز بيروكسيد الهيدروجين في نسيج الكبد الرطب.

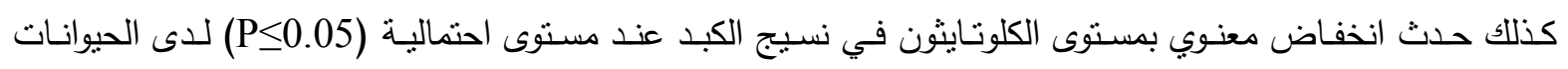

المعاملة بحامض الستريك بتراكيز 250، 500، 1000 ملغم/كغم من وزن الجسم وبفترات مختلفة كما موضح في الجدول (3) إذ فئ

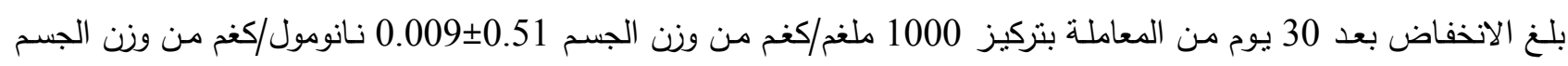

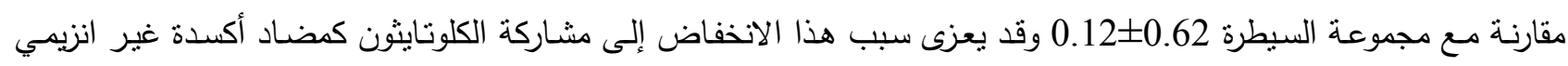
(داخلي المنشأ) في منع الأكسدة الذي أحدثه حامض الستريك من خلال الإزالة المباشرة للجذور الحرة ولزيادة بيروكسيد الهيدروجين داخل نسيج الكبد اذ يعد الخط الدفاعي ضد سمية عدد كبير من المركبات الكيميائية والعقاقير التي تدخل جسم الكائن الحي لإئي 
المتمتلة بعدد من الآليات الخلوية من خلال الدفاع الخلوي عن ذلك النسيج المعرض للجذور الحرة، ان الكلونايثون يلعب دورا مهما في تفاعلات الأكسدة والاختزال وباعتبار الكبد المصدر الرئيسي للكلوتايثون الموجود خارج الخلابا ولتحول الكلوتايثون في الثكل المختزل GSH إلى الثكل المؤكسد GSSG بزيادة تراكيز بيروكسيد الهيدروجين في نسيج الكبد وهذا المركب ينتج الثكل المؤكسد من الكلوتايثون (احمد والهلالي، 2010).

الجدول 1: تأثير تركيز حامض الستريك على مستوى البروتين الكلي والألبومين في مصل الام

\begin{tabular}{|c|c|c|c|c|}
\hline \multicolumn{2}{|c|}{ مستوى الالبومين (غم/100مل) المعل } & \multicolumn{2}{|c|}{ مستوى البروتين الكلي (غم/100مل) } & \multirow{2}{*}{ المجاميع } \\
\hline 30 يوم & 15 يوم & 30 يوم & 15 يوم & \\
\hline $2.4 \pm 4.3$ & $2.6 \pm 4.5$ & $1.18 \pm 7.21$ & $1.17 \pm 7.20$ & مجموعة السبطرة \\
\hline $1.7 \pm 4.3$ & $3.1 \pm 4.2$ & $2.5 \pm 7.6$ & $3.7 \pm 7.40$ & بحامض الستريك 250ملمة الحيوانات المعاملة من وكغ \\
\hline$* 1.9 \pm 4.6$ & $2.8 \pm 4.7$ & $* 2.7 \pm 7.6$ & $3.1 \pm 7.2$ & بحامض الستريك الحيوانات المعاملة م00ملغم/كغم \\
\hline $3.7 \pm 4.8$ & $3.6 \pm 4.9$ & $* 3.9 \pm 7.9$ & $4.1 \pm 7.6$ & بحامض الستريك مجمة الحيوانات المعاملة 1000 ملغم/كغم \\
\hline
\end{tabular}

المعدل والخطأ القياسي لستة مكررات.

عدد الحيوانات لكل مجموعة =6.

* تنشير الى وجود فرق معنوي عند مسنوى احتمالية (P<0.05).

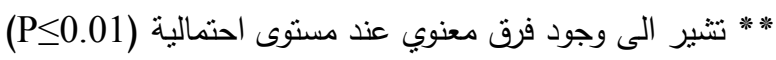

الجدول 2: تأثير تراكيز حامض الستريك على فعالية انزيمي ALT و AST

\begin{tabular}{|c|c|c|c|c|}
\hline \multicolumn{2}{|c|}{ فعالية انزيم المعدل 土 الخطأ القياسي } & \multicolumn{2}{|c|}{ 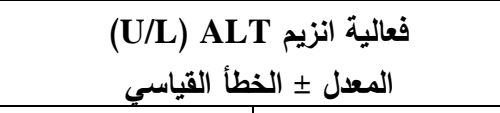 } & \multirow{2}{*}{ المجاميع } \\
\hline 30 يوم & 15 يوم & 30 يوم & 15 يوم & \\
\hline $4.3 \pm 93.1$ & $3.5 \pm 90.81$ & $2.31 \pm 50.7$ & $2.21 \pm 50.2$ & مجموعة السبطرة \\
\hline $7.2 \pm 115$ & $5.3 \pm 192.13$ & $* 2.7 \pm 70.13$ & $3.27 \pm 65.16$ & الستريك 250ملغمعة الحيوانات المعاملة بحامض من وزن الجسم \\
\hline$* 8.3 \pm 125$ & $7.4 \pm 107.1$ & $* 2.25 \pm 80.9$ & $* 4.25 \pm 79.1$ & الستريك 500ملغمعة الحيوانات المعاملة بحامض من وزن الجسم \\
\hline$* 8.1 \pm 137$ & $* 8.2 \pm 115$ & $* 7.21 \pm 95$ & $* 5.1 \pm 85.3$ & الستربك 1000موعة الحيوانات المعاملة بحامض مغن من وزن الجسم \\
\hline
\end{tabular}

عدد الحيوانات لكل مجموعة =6.

* *تـير الـى وجود فرق معنوي عند مستوى احتماليـة
المعدل والخطأ القياسي لستة مكررات.

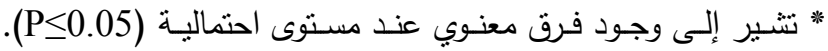

. $(\mathrm{P} \leq 0.01)$ 
انتصار غانم طه

\begin{tabular}{|c|c|c|}
\hline 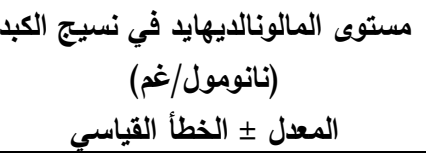 & مستوى الكلوتاثيون في نسيج الكبل (نانومول/غم) & فترة المعاملة \\
\hline $1.3 \pm 172$ & $0.12 \pm 0.62$ & مجموعة السبطرة \\
\hline$* 2.09 \pm 180$ & $0.07 \pm 0.60$ & بحامض الستريك مجمة الحيوانات المعاملة \\
\hline$* * 4.1 \pm 186$ & $* 0.01 \pm 0.58$ & 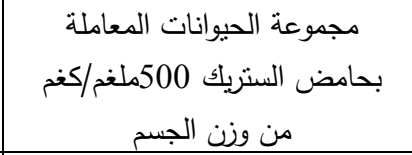 \\
\hline$* * 4.5 \pm 195$ & $* * 0.009 \pm 0.51$ & 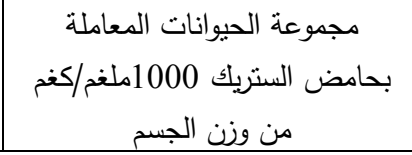 \\
\hline & & عدد الحيوانات لكل مجموعة القياسي لستة مكررات. \\
\hline
\end{tabular}

\section{المصادر العربية}

احمد، طـارق يونس، الهلالكي، لوؤي عبد، (2010). "الكيمياء الحياتيـة". الجزء الثاني، دار ابن الأثير للطباعـة والنشـر، جامعـة

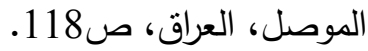

\section{المصادر الأجنبية}

Aktac, T.; Kaboglu, A.; EvtanK, F.; Elcinci, F., Huseyn, G. (2002). The effect citric acid oxidant and benzoic acid cantimicro biaa gent on mose liver biochemical and histopathological .

Aktac, T.; Kaboglu, A.; Balcur, E.; Kavakas, S. (2003). The short-term effect of single toxic dose of citric acid in mice. J. Cell. Mole. Bio., 2,19-23.

Berg, J.M.; Thmocykal, S. (2002). "Biochemistry". $5^{\text {th }}$ ed. Wh. Freeman and company. 144p.

Berovic, M.; Legisa, M. (2007). Citric Acid production. Bio. Ann. Rer., 13,303-343.

Derewenda, A.; Zygmunt, S. (2007). On wine chirality and crystal ography. Actacrys. 64(1), 246258.

Frank, H.; Venhoff, D. (2005). "Citric Acid Uillmann's Encyclopedia of Industrial Chemistry". WeinheimWiley. Rch. pp.13-19.

Garden, J.; Robert, D.; Robinson, A.; Taylor, S. (2003). Evaluation of the provision of single use citric acid sacthesto injection drng user Scottish center forin fection and environmental helth cross. Proc. Nat. Aca., 92, 22-29

Gilbert, H.S.; Stnmp, P.P.; Reth, E.F. (1984). Method to correct for errors caused the generation of intrefering compound injuring eruthrocyte lipid peroxidation. Analyt. Bioch .72, 282-286.

Jennifer, D.; Findar, D.P. (1982). Albumin bromocresol green a case of laboratory conservatism. Clin. Chem, 28(6), 1407-1408.

Kingsley, G.R. (1949). The direct biuret method for determination of serum protein. J. Clin. Lab., 9(27), 840-847.

Lotfy, W.A.; Ghanenk, A. (2007). Citric acid production and isolate optimization of processs parameters through statistical expermintal desigus. Bio. Sou. Tech., 30, 90-94.

Moron, M.SD.; Eriewe, J.; Wmennervik, E.F. (1979). Level of glutathione, glutathione redutase and glutathione stranderase activities in rat luag \& liver. Bio. Bio Phs. Acta., 852, 67-78.

Penniston, S.Y.; Holmes, RP.; Assimos, D.G. (2008). Quantitive lime juice and commercially avalible. J. Endo 22(3), 567-570. 


$$
\text { تأثثير حامض الستريك على بعض المتغيرات.................. }
$$

Reitman, S.; Frankel, S.A. (1957). Colometric method for the determination of serum glutamicoxaloacetic and glutamicpyrovictransam. nase ". Am. J. clin. 28, 56-63.

Rouhoiiah, N.; Onr Mohammad, I.; Seyed, M.; Hosseinal, H. (2010). Effect of dietary acidfaction on some blood parameters and weekly performance broiler chickens. J. Animal. Rete. Adv., 9(24), 3092-3097.

Steel, G.; Torrir, J. (1980). "Principle and Procedure of Statistics". $2^{\text {nd }}$ ed. New York Mc. Graw Hill Book. Co Inc 64P.

Toro, G.; Tckenaan, P.G. (1975). "Pracical Clinical Chemistry, Little Brown and Company". (Inc) USA. pp. 497-506.

Tulin, S. (2002). Effect of citric acid on tissue in mice. Animal. Chem., 8(22), 3012-3015.

Xiaoguang, C.; Qiongxia, L.V.; Yumei, L.; Wen Deng, K. (2013). Study injury effect of food additive citric acid on liver tissue in mice. Cytotechology. 3 (4), 211. 